\title{
A Call For Embedding Dignity In Humanitarian Technologies*
}

\author{
Reem Talhouk $^{\dagger 1}$, Kyle Montague ${ }^{1}$, Andrew Garbett ${ }^{1}$, Vera Araújo-Soares ${ }^{2}$, Chaza Akik ${ }^{3}$, Hala \\ Ghattas $^{3}$, Balsam Ahmad ${ }^{2}$, Madeline Balaam ${ }^{4}$
}

\author{
10 pen Lab \\ 2Institute of Health \& Society \\ Newcastle upon Tyne, U.K. \\ r.r.talhouk2, \\ firstname.lastname@ncl.ac.uk
}

\author{
${ }^{3}$ Center for Research on \\ Population and Health \\ Beirut, Lebanon \\ ca36,hg15@aub.edu.lb
}

\author{
${ }^{4} \mathrm{KTH}$ Royal Institute of \\ Technology \\ Stockholm, Sweden \\ balaam@kth.se
}

\begin{abstract}
Increasingly, technologies are being designed to support refugees. While HCI research has explored several aspects of refugee experiences, the importance of embedding the principle of dignity within technological designs is yet to be explored. In this paper we focus on the theme of dignity that was a prominent theme across three research projects we conducted with Syrian refugee communities in Lebanon. We show that the experiences of refugee participants are characterised by a loss of dignity, as well as by attempts to maintain dignity that may be mediated by technology. By highlighting the value given to dignity by our participants we emphasise the need for designers and HCI researchers to consider how technologies may create a space in which dignity is maintained and dignified interaction may take place.
\end{abstract}

\section{CCS CONCEPTS}

- Human-centered computing • Human computer interaction $(\mathrm{HCI}) \bullet$ Empirical studies in HCI

\section{KEYWORDS}

Refugees, Dignity, Digital Humanitarianism, Design Research

\section{ACM Reference format:}

Reem Talhouk, Kyle Montague, Andrew Garbett, Vera Araújo-Soares, Chaza Akik, Hala Ghattas, Balsam Ahmad and Madeline Balaam. 2019. A Call for Embedding Dignity in Humanitarian Technologies. In Proceedings of the $9^{\text {th }}$ International Conference on Communities and Technologies (C\&T'19). ACM, New York, NY, USA, 4 pages. Permission to make digital or hard copies of all or part of this work for personal or classroom use is granted without fee provided that copies are not made or distributed for profit or commercial advantage and that copies bear this notice and the full citation on the first page. Copyrights for components of this work owned by others than the author(s) must be honored. Abstracting with credit is permitted. To copy otherwise, or republish, to post on servers or to redistribute to lists, requires prior specific permission and/or a fee. Request permissions from Permissions@acm.org.

C\&T 2019, June 3-7, 2019, Vienna, Austria

(C) 2019 Copyright is held by the owner/author(s). Publication rights licensed to ACM.

ACM ISBN 978-1-4503-7162-9/19/06 ...\$15.00

https://doi.org/10.1145/3328320.3328373 https://doi.org/10.1145/1234567890

\section{Introduction}

The use of digital technologies within humanitarian contexts has been posited to be "key to the development of solutions to humanitarian problems" [15] as it transforms how aid is being provided. We have witnessed the establishment of innovation groups within humanitarian and development aid organizations [18,29], as well as an increasing interest in designing technologies for refugees among Human-Computer Interaction (HCI) researchers and technology designers[1,24,28]. While the positive potential of humanitarian technologies has dominated most of the discussions within digital humanitarianism, there has been a call for a critical inquiry that examines how humanitarian technologies may shift relationships between aid organizations and their beneficiaries [20]. Academics have highlighted the need to embed values in humanitarian technologies that move away from consumer centered design of digital services and account for socio-cultural and political environments in which humanitarian technologies would be deployed $[19,20]$. Several scholars have responded to this call for critical reflections on the role of technologies in humanitarian response by discussing how best to embed humanitarian principles within the design, development and deployment of humanitarian technologies [10]. However, such academic rhetoric $[10,19,20]$ has been situated in designing technologies from the perspective of humanitarian organizations rather than the perspective of refugees themselves.

HCI research has focused on designing technologies that account for the challenges refugees face when they become refugees and as they transition into new host communities $[2,4,11,12,14]$. Al Mohammad \& Vyas [2-4] highlighted that refugee experiences in Australia are characterized by social isolation, cultural barriers, mistrust, displacement trauma and shame when requesting help. Additionally, studies have 
reported information deficit being a major challenge experienced by refugees as they journey to new countries $[12,21]$. Coles-Kemp et al [11] recount how refugees and asylum seekers feel a constant pressure to remain connected, often via mobile phones, to their previous lives and their new environments in order to cope with their new contexts. Design workshops in Za'atari camp in Jordan identified that refugee youth hope that technologies may aid in countering challenges they are experiencing such as inaccessible schooling [13]. Experiences of loss of dignity and attempts to maintain dignity by refugees are still yet to be explored within HCI literature. However, the value of dignity was a main theme that emerged from data collected from three research engagements with Syrian refugee communities. We highlight the value that refugees place on maintaining dignity and how that can be mediated through technology. Consequently, we call for technology designers and HCI researchers to reflect on how dignity may be embedded in humanitarian technologies. For this paper we rely on Formosa and Mackenzies' definitions of dignity [15]. Dignity can be defined as status dignity and achievement dignity where status dignity refers to "the respect worthy status of a person" and achievement dignity to "acting in a dignified way or to be in a dignified state" [15].

\section{Methods}

The findings of this paper are a result of engagements with Syrian refugee women residing in informal settlements in rural Lebanon as part of three research projects $(n=87)$. The first two studies [26,27] explored refugee experiences in accessing healthcare services through engaging with five Syrian refugee communities through focus groups $(n=59$, P1...P59) and the subsequent piloting and evaluation of a technology that aimed to improve access to healthcare with one of the refugee communities ( $n=15$, P60...P75). Piloting and evaluating the technology entailed nine focus groups. The third study aimed to explore refugee experiences of food insecurity and the role of technologies in improving household food security (n=13, P76...P87) with another refugee community. In the third study participants engaged in five design engagements in which participants constructed narratives of coping with food insecurity and documented their experiences through the co-creation of a booklet. We have provided more detailed accounts of the methods and the findings in [25-27]. Audio recordings from all the engagements and focus groups were transcribed and thematically analyzed $[6,7]$ by the first author who is fluent in Arabic, the language in which this research was conducted. Throughout our engagements with participants in codesigning and evaluating digital health technologies, the themes of loss of dignity and attempts to maintain dignity were emergent across the dataset as a whole, when the data was thematically analysed [6,7]. It is the prominence of these themes within our data that has motivated us to unpack them in this paper and call for HCI researchers and technology designers to consider how dignity may be embedded in technologies.

\section{Findings}

Our findings reflect on how dignity is lost upon becoming a refugee and how this loss of dignity is experienced in day-today interactions. Additionally, we highlight the value that refugee participants placed on dignity and how technology may mediate and facilitate the maintaining of dignity.

\subsection{Loss of Dignity Upon Becoming a Refugee}

Participants from all three case studies described their experiences of becoming refugees to be intimately tied with a loss of dignity, "We had everything, our homes were great and we lived with dignity. Why did this happen to us?" [P78]. They attributed this loss of status dignity as being linked to their label of being refugees:

\section{"Syrians [refugees] are being insulted every day" [P10]}

"We wish that the people in the village [where she lives] were more understanding... and didn't think that since we are from a war stricken country that means we are uncultured" [P80]

\subsection{Loss of Dignity as Experienced in Day-to- Day Interactions}

Participants described several day-to-day interactions that cut across multiple services they were accessing that they described to be undignified, and that reflected a loss of achievement dignity. When providing an account of accessing a hospital one participant, P10, said, "this is not how you treat people. Let me be Syrian or whatever this [the way she was treated at the hospital] was not respectful" while another described treatment at clinics to be inhumane. Participants expressed skepticism that communication with healthcare providers mediated through technologies might allow for more dignified communication with healthcare providers. They considered that technologically mediated communication would simply mimic their current undignified experiences. Experiences of embarrassment were also reflected on by participants as they recounted narratives of coping with food insecurity. Participants indicated that before becoming refugees they did not have to budget for buying food and found the experience of having to return food items at the till of the grocery store if the bill exceeds their budget to be embarrassing.

"I am too embarrassed to tell him [the shop owner] 'don't give me the whole pack of stock cubes I just want two cubes" [P87]

Participants indicated that accessing prices of grocery items online beforehand would allow them to avoid such experiences, in shops where the prices of items are not publicly displayed. 


\subsection{Value in Maintaining Dignity}

Participants from across the studies continuously reflected on the difficult decisions they are making in order to maintain achievement dignity. Participants living in an informal settlement made up of unfinished apartment buildings said that they made the choice to pay more rent in order to maintain elements of their previous dignified lives for themselves and for their families.

"we would rather have less food for our children than live like that [in tents]" [P81]

Another participant recounted how despite being food insecure she spends money buying her children clothing in order to look presentable, "it is important that my children leave the house looking presentable, I don't want people to pity us". Similarly, women echoed the importance of ensuring that their children do not feel that they are food insecure and are refugees.

"My children know that we cannot always buy them what they want, but I never tell them it is because we are refugees" [P77]

"We give the children a bit of money, to buy snacks at school so that they don't feel like they are different from the other children" [P60]

Participants often sought out specific service providers based on their reputation for providing dignified treatment. One participant indicated that she is paying for transportation, at the expense of other financial needs, to go to a dental clinic in another town because the nurses there "treat us [Syrian Refugees] much better than others [nurses]" [P76]. When reflecting on interactions with shop owners where they purchase food, participants indicated that prices and distance of shops influence their choice of shops, but equally so does whether the shop owner treats them in a respectful manner. One participant explained, "Why should we benefit them [shop owners that are disrespectful]" [P79]. When exploring how technologies may facilitate their interactions with shop owners, participants indicated that having shop ratings available online that specifically reflect shop owners' treatment of refugees would be essential.

\section{Discussion}

The value that refugee participants placed on maintaining dignity resonates with economic development theories that emphasize that within contexts of austerity, economic development is inhibited if communities are unable to "realize life with human dignity"[15,22]. The protracted nature of the Syrian conflict places Syrian refugees in the humanitariandevelopment nexus, making notions of dignity highlighted in economic development ever more relevant. Our findings indicate that our participants experience both a loss of status dignity upon becoming refugees and achievement dignity as they interact with others in their new environment. Participants recounted undignified experiences that cut across several services they access to overcome their day-to-day challenges. This indicates that while maintaining dignity may be a challenge in itself, it is frequently experienced in parallel with other challenges they face such as accessing food and healthcare.

While loss of status dignity seems to be inherent in participants' status as refugees, our findings indicate that technologies may play a role in maintaining achievement dignity. Indeed information platforms have the potential to help maintain dignity by reducing information asymmetry. Indeed participants indicated that making available information such as food prices and online ratings of other refugees' experiences with service providers may facilitate the maintenance of dignity. In other contexts, technologies such as FeedFinder [5,23], allow community members to share experiences through geo-location ratings. Such tools may be used by refugee communities to not only inform one another of where respectful experiences can be found but also make more visible their negative experiences that are characterized by a loss of achievement dignity. However, participants also expressed skepticism that technologies that facilitate interactions with service providers can allow for achievement dignity to be maintained. This stresses the need for HCI researchers and technology designers to consider how we can embed dignity within humanitarian technologies, where embedding dignity means that maintaining dignity is an aim that should be inherent in the designs of humanitarian technologies and given great consideration when configuring humanitarian technologies. In his reflection on the principles of human-centered design, Buchanan recommends that human dignity be put center stage from the onset of design processes in order to ensure that technological designs maintain and promote human dignity $[8,9]$. To do so in refugee contexts entails critical reflection, by both designers and participants, on how a technology may produce tangible outcomes that would benefit refugee communities, such as $[14,26,31,32]$, and in addition mediate and facilitate 'dignified interactions' through the provision of information or through how they configure interactions. Design approaches such as Interaction design [17], Experience Centered Design [30] and Value Sensitive Design [16] , that bring forth refugee perspectives in to the design of humanitarian technologies, may surface experiences in which the maintenance of dignity is required. Additionally, they may create a space where refugee participants can explore how dignified interactions with service providers might be configured and facilitated through technologies.

\section{Conclusion}

Our paper calls for technology designers and HCI researchers to consider how dignity may be embedded within 
technological designs. We show how refugee experiences are characterized by a loss of dignity as well as the high value refugee participants place on maintaining dignity. We therefore call for HCI researchers and technology designers to consider how dignity may be maintained through the provision of information and technologically mediated interactions.

\section{ACKNOWLEDGMENTS}

We would like to thank participants for welcoming us in to their homes and their lives. This work was funded by an EPSRC award EP/L016176/1 (Centre for Doctoral Training in Digital Civics).

\section{REFERENCES}

[1] Konstantin Aal, Vasilis Vlachokyriakos, Anne Weibert, and Karen Fisher. 2018. Refugees \& Technology: Determining the Role of HCI Research. In Proceedings of the Conference on Supporting Groupwork (GROUP '18), $362-$ 364. https://doi.org/10.1145/3148330.3152160

[2] Asam Almohamed and Dhaval Vyas. 2016. Vulnerability of Displacement: Challenges for Integrating Refugees and Asylum Seekers in Host Communities. In Proceedings of the Australian Conference on ComputerHuman Interaction of (OzCHI'16), 125-134. https://doi.org/10.1145/3010915.3010948

[3] Asam Almohamed, Dhaval Vyas, and Jinglan Zhang. 2017. Rebuilding social capital: Engaging newly arrived refugees in participatory design. In Proceedings of the 29th Australian Conference on Computer-Human Interaction (OZCHI '17), 59-67. http://doi.org/10.1145/3152771.3152778

[4] Asam Almohamed, Dhaval Vyas, and Jinglan Zhang. 2018. Designing for Refugees: Insights from Design Workshop. In Proceedings of the 30th Australian Conference on Human - Computer Interaction, 92-96. http://doi.org/10.1145/3292147.3292196

[5] Madeline Balaam, Rob Comber, Ed Jenkins, Selina Sutton, and Andrew Garbett. 2015. FeedFinder: A Location-Mapping Mobile Application for Breastfeeding Women. Proceedings of the ACM CHI'15 Conference on Human Factors in Computing Systems 1: 1709-1718. http://doi.org/10.1145/2702123.2702328

[6] Virginia Braun and Victoria Clarke. 2006. Using thematic analysis in psychology. Qualitative Research in Psychology 3, 2: 77-101. http://doi.org/http://dx.doi.org/10.1191/1478088706qp063oa

[7] Virginia Braun and Victoria Clarke. 2013. Successful Qualitative Research: A Practical Guide for Beginners. SAGE.

[8] Richard Buchanan. 2001. Human Dignity and Human Rights: Toward a Human-Centered Framework for Design. Reshaping South Africa by Design. https://doi.org/10.1162/074793601750357178

[9] Richard Buchanan. 2001. Human Dignity and Human Rights: Thoughts on the Principles of Human-Centered Design. Design Issues 17, 3: 35-39. http://doi.org/10.1162/074793601750357178

[10] Isabelle Voneche Cardia, Adrian Holzer, Carleen Maitland, and Denis Gillet. 2017. Towards a Principled Approach to Humanitarian Information and Communication Technology. http://doi.org/10.1145/3136560.3136588

[11] Lizzie Coles-Kemp, Rikke Bjerg Jensen, and Reem Talhouk. 2018. In a New Land: Mobile Phones, Amplified Pressures and Reduced Capabilities. In Proceedings of the CHI Conference on Human Factors in Computing Systems (CHI'18), 584. https://doi.org/10.1145/3173574.3174158

[12] Ana Maria Bustamante Duarte, Auriol Degbelo, and Christian Kray. 2018 Exploring Forced Migrants (Re)settlement \& the Role of Digital Services. In Proceedings of 16th European Conference on Computer-Supported Cooperative Work (ECSCW'18), 1-18. http://doi.org/10.18420/ecscw2018

[13] Karen E Fisher, Katya Yefimova, and Eiad Yafi. 2016. "Future ' s Butterflies :" Co-Designing ICT Wayfaring Technology with Refugee Syrian Youth. In Proceedings of the Conference on Interaction Design and Children (IDC'16), ACM, 25-36. http://dx.doi.org/10.1145/2930674.2930701

[14] Karen Fisher, Reem Talhouk, Katya Yefimova, et al. 2017. Za'atari Refugee Cookbook: Relevance, Challenges and Design Considerations. In Proceedings of the CHI Conference Extended Abstracts on Human Factors in Computing Systems (CHI EA '17), 2567-2583. https://doi.org/10.1145/3027063.3053235

[15] Paul Formosa and Catriona Mackenzie. 2014. Nussbaum, Kant, and the Capabilities Approach to Dignity. January: 875-892. http://doi.org/10.1007/s10677-014-9487-y

[16] Batya Friedman, Peter H. Kahn, Alan Borning and Alina Huldtgren, 2013. Value Sensitive Design and Information Systems. . Springer, Dordrecht, 55 95. http://doi.org/10.1007/978-94-007-7844-3_4

[17]Kristina Höök, Anna Ståhl, Petra Sundström, and Jarmo Laaksolaahti. 2008 Interactional empowerment. Proceeding of the twenty-sixth annual CHI conference on Human factors in computing systems - CHI '08: 647. http://doi.org/10.1145/1357054.1357157

[18] Unhcr Innovation. 2014. UNHCR Innovation. UNHCR Innovation. Retrieved September 20, 2015 from http://innovation.unhcr.org/

[19] Katja Lindskov Jacobsen. 2015. The politics of humanitarian technology: good intentions, unintended consequences and insecurity. Routledge.

[20] Kristin Bergtora Sandvik, Maria Gabrielsen Jumbert, John Karlsrud, and Mareile Kaufmann. 2014. Humanitarian technology: a critical research agenda. International Review of the Red Cross 96, 893: 219-242. http://doi.org/10.1017/S1816383114000344

[21] Maximilian Schreieck and Manuel Wiesche. 2017. Supporting Refugees in Every Day Life - Intercultural Design Evaluation of an Application for Local Information. In Proceedings of the Pacific Asia Conference on Information Systems, 1-12.

[22] Amartya Sen. 2003. Development as Capability Expansion. Readings in Human Development: Concepts, Measures and Policies for a Development Paradigm: 41-58.

[23] Emma Simpson, Rob Comber, Andrew Garbett, Ed Ian Jenkins, and Madeline Balaam. 2017. Experiences of Delivering a Public Health Data Service. In Proceedings of the CHI Conference on Human Factors in Computing Systems (CHI'17), http://doi.org/10.1145/3025453.3025881

[24] Reem Talhouk, Syed Ishtiaque Ahmed, Volker Wulf, Clara Crivallero, Vasilis Vlachokyriakos, and Patrick Olivier. 2016. Refugees and HCI SIG : The Role of HCI in Responding t o the Refugee Crisis. In Proceedings of the CHI Extended Abstracts on Human Factors in Computing Systems (CHI'16), 10731076. https://doi.org/10.1145/2851581.2886427

[25] Reem Talhouk, Madeline Balaam, Austin L. Toombs, et al. 2019. Involving Syrian Refugees in Design Research: Lessons Learnt from the Field. In Proccedings of Designing Interactive Systems (DIS19), In Press. https://doi.org/10.1145/3322276.3322335

[26] Reem Talhouk, Tom Bartindale, Kyle Montague, et al. 2017. Implications of Synchronous IVR Radio on Syrian Refugee Health and Community Dynamics *. In Proceedings of the 8th International Conference on Communities and Technologies (C\&T'17), 1-10. http://doi.org/10.1145/3083671.3083690

[27] Reem Talhouk, Sandra Mesmar, Anja Thieme, et al. 2016. Syrian Refugees and Digital Health in Lebanon: Opportunities for Improving Antenatal Health. Proceedings of the CHI Conference on Human Factors in Computing Systems (CHI'16), 331-342. http://doi.org/10.1145/2858036.2858331

[28] Reem Talhouk, Vasilis Vlachokyriakos, Konstantin Aal, et al. 2017. Refugees \& HCI Workshop: The Role of HCI in Responding to the Refugee Crisis. In Proceedings of the International Conference on Communities and Technologies (C\&T'18), http://doi.org/10.1145/3027063.3027076

[29] UNICEF Innovation. 2016. A team of innovators, a UNICEF staff member, and an NGO walk into a hackathon. Retrieved September 19, 2017 from 
https://blogs.unicef.org/innovation/team-innovators-unicef-staffmember-ngo-walk-hackathon/

[30] Peter Wright and John McCarthy. 2010. Experience-Centered Design: Designers, Users, and Communities in Dialogue. In Synthesis Lectures on Human-Centered Informatics, M. Carroll, John (ed.). Morgan \& Claypool, 1123. http://doi.org/10.2200/S00229ED1V01Y201003HCI009

[31] Ying Xu and Carleen Maitland. 2019. Participatory data collection and management in low-resource contexts. Proceedings of the Tenth International Conference on Information and Communication Technologies and Development - ICTDX '19, 1-12. http://doi.org/10.1145/3287098.3287104

[32] Ying Xu, Carleen Maitland, and Brian Tomaszewski. 2015. Promoting Participatory Community Building in Refugee Camps with Mapping Technology. In Proceedings of the International Conference on Information and Communication Technologies and Development (ICTD '15). http://dx.doi.org/10.1145/2737856.2737883 